\title{
Diffuse Lewy body disease: correlative neuropathology using anti-ubiquitin immunocytochemistry
}

\author{
GRAHAM LENNOX,* JAMES LOWE,** MICHAEL LANDON, $\dagger$ E JANE BYRNE, \\ $R$ JOHN MAYER, $\dagger$ RICHARD B GODWIN-AUSTEN*
} From the Departments of Neurology,* Pathology, ${ }^{* *}$ Biochemistry $\dagger$ and Health Care of the Elderly, $\ddagger$ Queen's
Medical Centre, Nottingham

SUMMARY Diffuse Lewy body disease is an important pathological substrate of the common syndrome of parkinsonian dementia. The new technique of anti-ubiquitin immunocytochemistry has been used in a correlative quantitative neuropathological study of fifteen cases of diffuse Lewy body disease, showing that the severity of dementia is related to cortical Lewy body density, whilst subcortical abnormalities make a much less significant contribution. Cortical senile plaques also appear to be part of the pathology of diffuse Lewy body disease and should not therefore be used as an isolated diagnostic criterion for Alzheimer's disease. Diagnostic criteria for diffuse Lewy body disease are discussed.

Diffuse Lewy body disease is a common neuropathological condition which is associated with clinical features of parkinsonian dementia. ${ }^{2}$ At least $20 \%$ of all patients with Parkinson's disease develop dementia. ${ }^{3}$ Conversely at least $30 \%$ of patients with dementia develop signs of parkinsonism..$^{4-11}$ The pathological basis of these parkinsonian dementia syndromes is poorly understood. The dementia has in the past generally been attributed to the pathological changes of Alzheimer's disease but recent clinicopathological studies have provided little or no support for this explanation, finding either no evidence of Alzheimer's disease ${ }^{1213}$ or only sparse changes ${ }^{1415}$ which fail to meet diagnostic criteria for Alzheimer's disease $^{1617}$ and do not correlate with the severity of the dementia. ${ }^{18}$ Diffuse Lewy body disease provides an alternative explanation.

Diffuse Lewy body disease is characterised by the presence of eosinophilic hyaline inclusion bodies (that is, Lewy bodies) in both subcortical and cortical areas. ${ }^{19-23}$ The brainstem Lewy bodies closely resemble those seen in Parkinson's disease both in morphology

Correspondence to: Dr Graham Lennox, Department of Neurology, University Hospital, Queen's Medical Centre, Nottingham, NG7 2UH, United Kingdom.

Received 17 February 1989 and in revised form 17 May 1989. Accepted 14 June 1989 and distribution (figure 1) and it seems reasonable to suppose that the brainstem pathology may be the bas of the parkinsonian features of diffuse Lewy body disease. The cortical Lewy bodies (which are unusua in uncomplicated Parkinson's disease ${ }^{24}$ ) may be the pathological basis of the dementia in diffuse Lewy body disease. However, quantitative studies to test this hypothesis have been hampered by the fact that cortical Lewy bodies are poorly circumscribed and difficult to identify using conventional haematoxylin and eosin ( $\mathrm{H}$ and $\mathrm{E})$ stains. In the present study of a series of fifteen cases of diffuse Lewy body disease we have therefore used the new technique of antiubiquitin immunocytochemistry, which identifies cortical Lewy bodies with greatly increased sensitivity and reliability ${ }^{25-27}$ and which also identifies neurofibrillary tangles and senile plaques. ${ }^{28-32}$ The technique allows quantitative study of large areas of cerebral cortex for the first time. We show a clear relationship between the cortical pathological features and the severity of dementia in diffuse Lewy body disease.

Preliminary data from this study have been reported elsewhere. ${ }^{233} 34$

Materials and methods

Pathological material

All 216 brains referred to this department from within the 
Nottingham Health District (population 616,000) during April 1985 to March 1986 were screened for the presence of cortical Lewy bodies using conventional $\mathrm{H}$ and $\mathrm{E}$ stains. Fifteen cases of diffuse Lewy body disease were identified on the basis of classical brainstem Lewy bodies and widespread cortical Lewy bodies. All 15 came from within the subgroup of 57 brains known to be from patients with dementia, a parkinsonian syndrome, or both. Diffuse Lewy body disease was identified in $27 \%$ of the cases with dementia in this survey, and was thus the commonest form of dementia after Alzheimer's disease. The clinical features of these cases have been described in detail elsewhere ${ }^{1}$ and are summarised in table 1 . The remaining 201 cases included a broad range of neuropathological conditions and ages.

The brains (or randomly selected half-brains in the eleven cases where the brain had been bisected sagittally in the fresh state and one half frozen for neurochemistry) were fixed in $10 \%$ formol saline for at least six weeks and then dissected in a standardised fashion. The cerebral cortex was divided into one centimetre coronal slices and blocks were taken from the major neocortical regions and from entorhinal cortex, periamygdaloid cortex and hippocampus; insular cortex and basal nucleus of Meynert at the level of the midpoint of the anterior commissure; and anterior cingulate gyrus from the same slice. The brainstem was sliced transversely at the level of the oculomotor nerve to obtain a substantia nigra block; longitudinally through pons for locus ceruleus; and transversely through medulla for dorsal vagal nucleus. These blocks were processed in paraffin wax and sectioned at 10 micrometres.

The sections were stained using $\mathrm{H}$ and $\mathrm{E}$, cresyl-fast violet, solochrome-cyanin, thioflavine $\mathbf{S}$, the Cross modification of Palmgren's silver stain $^{35}$ and anti-ubiquitin immunocytochemistry. ${ }^{36}$ Anti-ubiquitin immunocytochemistry was performed using a rabbit polyclonal antibody which showed high specificity for ubiquitin-protein conjugates in vitro and in tissue sections as previously described ${ }^{2536}$ with a streptavidin-biotin-peroxidase detection system. ${ }^{37}$ The antibody clearly identified both brainstem and cortical Lewy bodies (figures 1 to 3 ), as well as neurofibrillary tangles and neuritic elements of senile plaques (figures 2 and 3 ) $^{28}$
Immunocytochemical staining was limited in two cases by the accidental discarding of some of the tissue after preliminary histology had been completed.

\section{Additional pathological material}

In addition to the large number of miscellaneous neuropathological cases examined in this series, seven brains were examined from patients who satisfied clinical and pathological criteria for the diagnosis of Parkinson's disease, matched for age and duration of illness, who showed no evidence of dementia (based on retrospective case note examination using the criteria described below). They were examined in the same way as the cases of diffuse Lewy body disease and serve as a non-demented Parkinson's disease comparison group. Two of these cases came from the 1985-86 series; the remainder from more recent files. Ten brains from age-matched patients who died with no evidence of neurological or psychiatric disease (by the same criteria) were used as normal controls for cell counts in substantia nigra and nucleus basalis of Meynert.

\section{Quantitative neuropathology}

Numbers of pigmented cells and eosinophilic inclusion bodies in the substantia nigra were counted in between one and four unilateral $\mathrm{H}$ and $\mathrm{E}$ sections. The area of maximum cell density in the nucleus basalis of Meynert was identified and marked on $\mathrm{H}$ and $\mathrm{E}$ or cresyl-fast violet sections; the number of large ( $>25$ micrometre diameter), Nisslcontaining, nucleated cells was counted in between 10 and 20 graticule fields (area $0.23 \mathrm{~mm}^{2}$ ) within this area to obtain an estimate of cell density, expressed as the number of cells $/ \mathrm{mm}^{2}$.

Cortical Lewy body density was assessed using antiubiquitin immunocytochemistry in the superior frontal gyrus, superior parietal lobule, anterior cingulate gyrus, inferior and middle temporal gyri, insular cortex, entorhinal cortex and in the cornu Ammonis and subiculum of the hippocampus. In the hippocampus the numbers of Lewy bodies, tangles and plaques were counted using an eyepiece graticule (area $0.23 \mathrm{~mm}^{2}$ ) in a minimum of 20 graticule fields selected at random throughout all four divisions of the cornu Ammonis, and at least a further $\mathbf{2 0}$ graticules from all four

Table 1 Clinical features in cases of diffuse Lewy body disease

\begin{tabular}{|c|c|c|c|c|c|c|c|}
\hline Case & Age at onset & & Durn (yrs) & Presentation & $\begin{array}{l}\text { Motor fec } \\
\text { levodopa }\end{array}$ & $\begin{array}{l}\text { and } \\
s e^{b}\end{array}$ & Dementia severity \\
\hline $\begin{array}{r}1 \\
2 \\
3 \\
4 \\
5 \\
6 \\
7 \\
8 \\
9 \\
10 \\
11 \\
12 \\
13 \\
14 \\
15\end{array}$ & $\begin{array}{l}74 \\
82 \\
58 \\
74 \\
68 \\
72 \\
73 \\
62 \\
75 \\
83 \\
65 \\
73 \\
71 \\
70 \\
83\end{array}$ & $\begin{array}{l}\mathbf{F} \\
\mathbf{M} \\
\mathbf{M} \\
\mathbf{F} \\
\mathbf{F} \\
\mathbf{F} \\
\mathbf{M} \\
\mathbf{M} \\
\mathbf{M} \\
\mathbf{F} \\
\mathbf{F} \\
\mathbf{M} \\
\mathbf{F} \\
\mathbf{F} \\
\mathbf{M}\end{array}$ & $\begin{array}{r}2 \\
3 \\
5 \\
5 \\
19 \\
8 \\
3 \\
4 \\
5 \\
3 \\
2 \\
8 \\
6 \\
7 \\
3\end{array}$ & $\begin{array}{l}\text { Parkinsonism } \\
\text { Parkinsonism } \\
\text { Parkinsonism } \\
\text { Parkinsonism } \\
\text { Parkinsonism } \\
\text { Parkinsonism } \\
\text { Both } \\
\text { Both } \\
\text { Both } \\
\text { Dementia } \\
\text { Dementia } \\
\text { Dementia } \\
\text { Dementia } \\
\text { Dementia } \\
\text { Dementia }\end{array}$ & $\begin{array}{l}\text { RBTGP } \\
\text { RBTG } \\
\text { RBTGP } \\
\text { RBTG } \\
\text { RBTGP } \\
\text { RBTGP } \\
\text { RBTGP } \\
\text { RBTGP } \\
\text { RBG } \\
\text { P } \\
\text { RGP } \\
\text { RBGP } \\
\text { RTG } \\
\text { RTGP } \\
\text { G }\end{array}$ & $\begin{array}{l}\text { Definite } \\
\text { Definite } \\
\text { Definite } \\
\text { Definite } \\
\text { Definite } \\
\text { Definite } \\
\text { No trial } \\
\text { Definite } \\
\text { Probable } \\
\text { No trial } \\
\text { No trial } \\
\text { Definite } \\
\text { Definite } \\
\text { Definite } \\
\text { No trial }\end{array}$ & $\begin{array}{l}\text { Severe } \\
\text { Mild } \\
\text { Severe } \\
\text { Moderate } \\
\text { Severe } \\
\text { Very severe } \\
\text { Severe } \\
\text { Very severe } \\
\text { Very severe } \\
\text { Severe } \\
\text { Very severe } \\
\text { Severe } \\
\text { Very severe } \\
\text { Very severe } \\
\text { Very severe }\end{array}$ \\
\hline
\end{tabular}

a: further clinical details are given in reference 1 .

b: $\mathbf{R}=$ extrapyramidal rigidity, $\mathbf{B}=$ bradykinesia, $\mathbf{T}=$ resting tremor,

$\mathbf{G}=$ parkinsonian gait, $\mathbf{P}=$ flexed postural deformity.

c: classified according to the stage model of Strub and Black. ${ }^{38}$ 


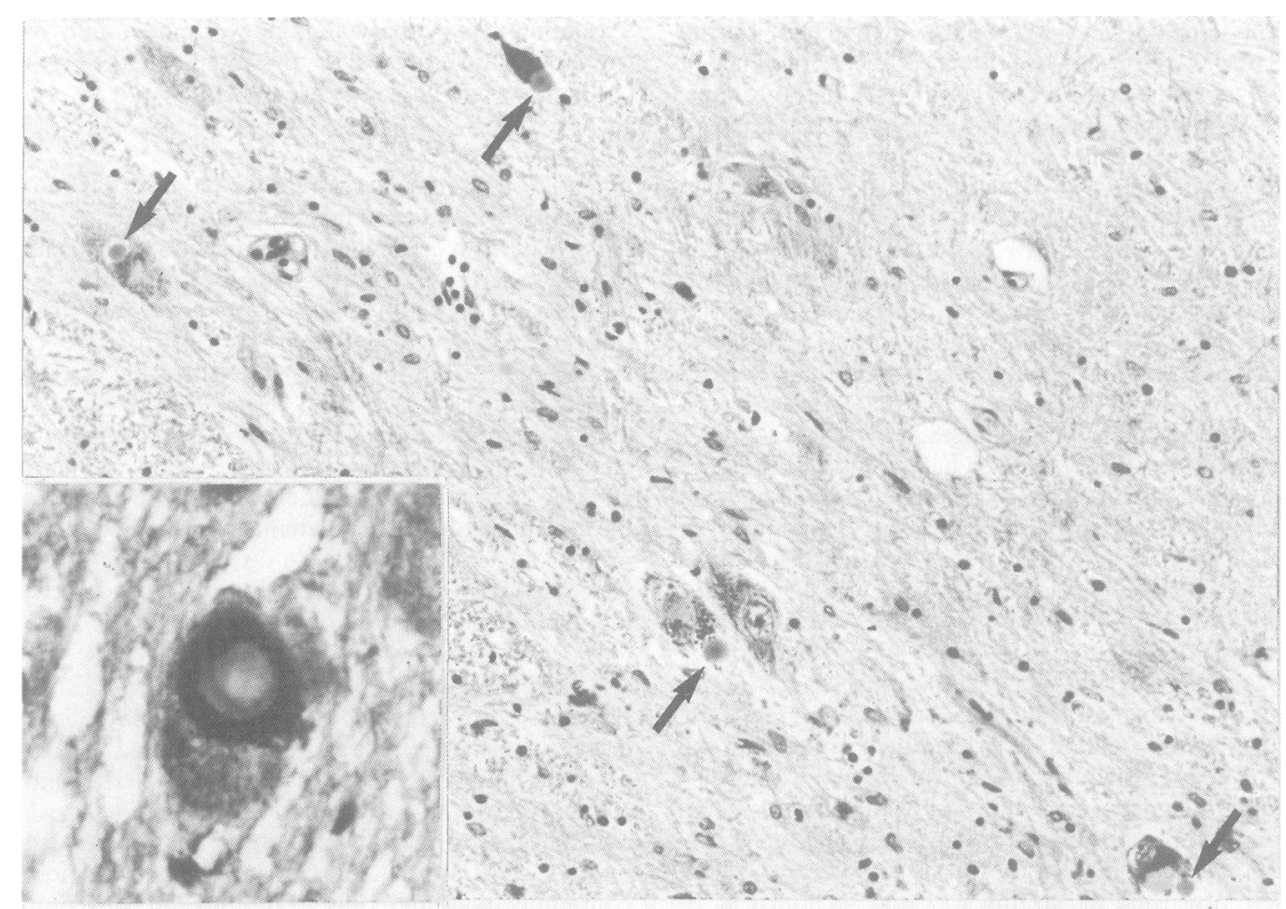

Fig 1 Substantia nigra (Case 15) showing cell loss, gliosis, pigment incontinence and classical Lewy bodies (arrows) in a high proportion of remaining neurons $(H$ and $E$, magnification $\times 210)$. Inset: brainstem Lewy body stained with anti-ubiquitin immunocytochemistry, showing intense peripheral immunoreactivity (magnification $\times 800$ ).

divisions of the subiculum. In the other cortical regions, large areas of the cortical ribbon were marked in ink on the coverslips before microscopic examination. Lewy bodies, tangles and plaques were counted by systematic parallel sweeps across the marked area at a magnification of $\times 250$ using the eyepiece graticule. The marked area was then projected and measured using a Kontron MOP Videoplan computerised planimetry system. The mean area counted in each case was $4 \cdot 2 \mathrm{~mm}^{2}$ (range $2 \cdot 3-9 \cdot 2 \mathrm{~mm}^{2}$ ) in the hippocampus and $56.2 \mathrm{~mm}^{2}$ (range $11.7-122.0 \mathrm{~mm}^{2}$ ) in each region of the cortex. Cortical Lewy bodies were defined as rounded, non-fibrillar, intensely immunoreactive inclusion bodies. Preliminary studies determined that this definition excluded neurofibrillary tangles and other forms of inclusion body ${ }^{25}$ it also excluded extracellular cortical Lewy bodies. Fibrillar perikaryal inclusion bodies were counted as neurofibrillary tangles (figure 3): this definition included small "wisps" of fibrillar material as well as classical "flame-shaped" tangles. Senile plaques with a clear neuritic component or compact core were counted; less clearly defined forms of senile plaque (so-called primitive or early plaques) were excluded.

In all cases Lewy body density was also assessed using conventional $H$ and $E$ stains of adjacent sections. The densities obtained by this method were proportional to those obtained using anti-ubiquitin immunocytochemistry but invariably lower, reflecting the difficulty in identifying cortical Lewy bodies using $H$ and E stains. Densities obtained $\overrightarrow{\vec{\theta}}$ with the anti-ubiquitin technique are therefore presented here. Neurofibrillary tangle and senile plaque densities were also assessed using conventional thioflavine $\mathbf{S}$ and Cross/ Palmgren stains in similar areas of adjacent sections. The ubiquitin and thioflavine $S$ techniques generally showed close agreement in the larger cortical regions and reasonable agreement in the hippocampus where the smaller areas studied produce a greater tendency to sampling error. Cross/ Palmgren stains gave much lower tangle and plaque counts. Densities obtained from thioflavine $S$ stains are presented here to facilitate comparison with other studies.

In the anterior cingulate gyrus the proportion of neurons containing Lewy bodies and the distribution of Lewy bodies within the cortical layers were determined in a minimum of 1500 neurones counted and examined using parallel sweeps, perpendicular to the surface of the gyrus, with an eyepiece graticule.

All neuropathological assessments were carried out on laboratory-coded slides without knowledge of the patient's identity or clinical details.

\section{Assessment of dementia severity}

All of these cases had spent time under the care of the Department of Health Care of the Elderly and had undergone detailed assessment of cognitive function. However, 


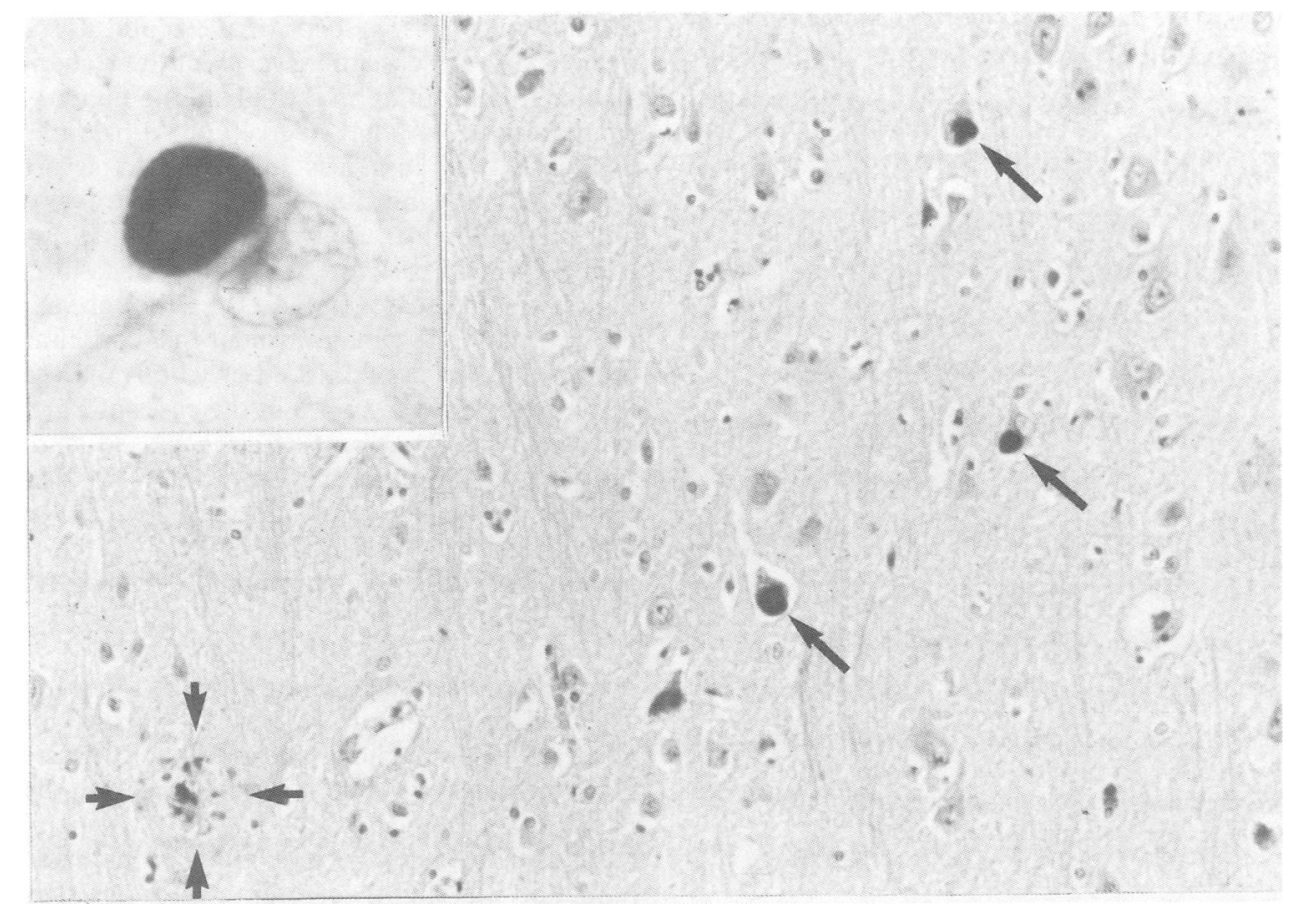

Fig 2 Entorhinal cortex (Case 8) stained with anti-ubiquitin immunocytochemistry showing cortical Lewy bodies in small neurons within the deeper cortical layers (arrows) and the neuritic elements of a senile plaque (arrow heads) (magnification $\times 210)$. Inset: cortical Lewy body showing that anti-ubiquitin immunoreactivity is again most intense at its periphery (magnification $\times 1100$ ).

several different tests were employed with different patients and many patients became too profoundly demented to attept any test in the later stages of their illness. Thus while a wealth of cognitive data had been assembled for these patients, no single standardised prospective measure of preterminal dementia severity could be applied to the entire group. Since the clinical progression of dementia severity conformed to the stage models proposed by Strub and Black $^{38}$ and by Reisberg $e t a l^{99}$ (in cases of primary degenerative dementia), cases were retrospectively classified according to these scales, using the standardised cognitive tests where relevant, supplemented by hospital medical and nursing records and general practitioner case notes. Many cases showed fluctuation in cognitive impairment in the early stages of their illnesses, but these disappeared with time. Classification was performed independently by two of us (GL and EJB) and verified by a third (RBGA): a very high degree of interobserver agreement was obtained. For simplicity the five point scale of Strub and Black (normal, mild, moderate, severe and very severe dementia) was used in correlations with the neuropathological data, but similar results were obtained using the Reisberg scale. In this series the distinction between severely and very severely demented patients is important; severely demented patients were dis- orientated in time and place, showed clear evidence of global cognitive impairment, required substantial assistance with activities of daily living and scored five or less on a 10 point mental status questionnaire, whilst very severely demented patients were in a vegetative state, being unable to communicate (either mute or uttering only incoherent noises), incontinent and bedbound, were totally dependent upon nursing support and scored 0 on a 10 point mental status questionnaire.

All assessments of dementia severity were made blind with regard to the neuropathological findings.

\section{Statistics}

Comparisons between cell counts and densities in cases and controls have been made using the Mann-Whitney $U$ test. Correlations between dementia severity and neuropathological measures have been made using the Spearman rank correlation coefficient (chosen because the dementia severity scale is non-linear and the cases are not evenly distributed within it). The correlation coefficients cited refer to the cases of non-demented Parkinson's disease and diffuse Lewy body disease taken as a whole, but similar, highly significant correlation coefficients are obtained if the cases of nondemented Parkinson's disease are excluded from the analysis. 


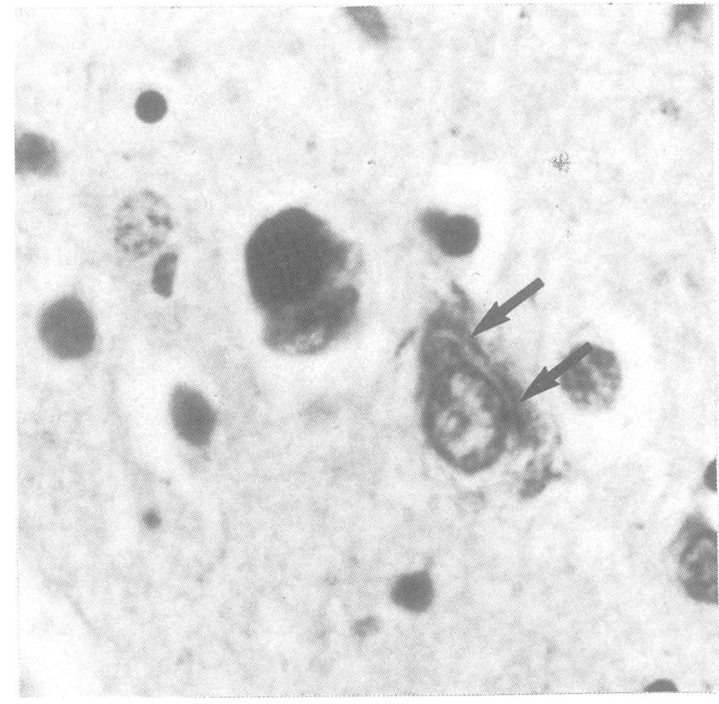

Fig 3 Adjacent neurons in the inferior temporal cortex (Case 15) containing a rounded cortical Lewy body (left) and liner fibrillar material constituting a neurofibrillary tangle (right; arrows) (magnification $\times 800$ ).

\section{Results}

\section{Brainstem pathology}

All fifteen cases of diffuse Lewy body disease showed loss of pigmented cells in the substantia nigra together with gliosis and classical Lewy body formation (figure 1). These changes were similar to those found in idiopathic Parkinson's disease. Lewy bodies, cell loss and gliosis were also found in other brainstem nuclei, in a distribution which again resembled that of Parkinson's disease: affected structures included the nucleus paranigralis, locus ceruleus and dorsal vagal nucleus. In each case the severity of these changes was similar to that found in the substantia nigra.

Quantitatively the degree of substantia nigra pigmented cell loss was moderate to severe when compared with normal controls; there was no significant difference between substantia nigra cell counts from the cases of diffuse Lewy body disease and Parkinson's disease (table 2), although a greater proportion of the remaining neurones contained Lewy bodies in the cases of diffuse Lewy body disease (mean 13.8 per section versus 4.6 in the cases of Parkinson's disease), perhaps indicating an increased tendency to Lewy body formation. There was no significant correlation between substantia nigra cell or Lewy body counts and dementia severity.

No case showed neurofibrillary tangles within brainstem structures.

\section{Nucleus basalis of Meynert pathology}

The nucleus basalis of Meynert also showed moderate to severe cell loss, gliosis and Lewy body formation in both diffuse Lewy body disease and non-demented Parkinson's disease. Cell density was significantly reduced in both diseases compared with controls. The reduction was slightly greater in cases of diffuse Lewy body disease than in cases of Parkinson's disease although this difference was not statistically significant (table 2). There was no significant correlation between dementia severity and cell density or Lewy body counts. Occasional neurofibrillary tangles were seen in all three groups, but in no case numbered more than two per section.

\section{Cortical Lewy body pathology}

Cortical Lewy bodies were not detected in the normal controls. Cortical Lewy bodies were very rare in the non-demented Parkinson's disease cases: none was identified using $\mathrm{H}$ and $\mathrm{E}$ stains, but with the more

Table 2 Subcortical and cortical pathology in diffuse Lewy body disease and Parkinson's disease

\begin{tabular}{|c|c|c|c|c|}
\hline $\begin{array}{l}\text { Cases } \\
\text { (number) }\end{array}$ & $\begin{array}{l}\text { Age at death } \\
\text { (mean years) }\end{array}$ & $\begin{array}{l}\text { Substantia nigra cell count } \\
\text { Mean, SE (range) }\end{array}$ & $\begin{array}{l}\text { Nucleus basalis of Meynert cell density } \\
\text { Cells } / \mathrm{mm}^{2}, S E \text { (range) }\end{array}$ & $\begin{array}{l}\text { Mean cortical Lewy body density } \\
\text { Lewy bodies } / \mathrm{mm}^{2}, S E \text { (range) }\end{array}$ \\
\hline $\begin{array}{l}\text { Normal } \\
\text { controls } \\
(n=10)\end{array}$ & $76 \cdot 3$ & $\begin{array}{l}814 \cdot 8,38 \cdot 9 \\
(489-926)\end{array}$ & $\begin{array}{l}89 \cdot 1,9 \cdot 9 \\
(61 \cdot 7-116 \cdot 5)\end{array}$ & 0,0 \\
\hline $\begin{array}{l}\text { Non- } \\
\text { demented } \\
\text { PD }^{d} \\
(n=7)\end{array}$ & $75 \cdot 2$ & $\begin{array}{l}190 \cdot 9,42 \cdot 0 \\
(87-384)\end{array}$ & $\begin{array}{l}38 \cdot 6,4 \cdot 5 \\
(23 \cdot 7-57 \cdot 1)\end{array}$ & $\begin{array}{l}0.006,0.003 \\
(0-0.02)\end{array}$ \\
\hline $\begin{array}{l}\text { DLBD } \\
(n=15)\end{array}$ & $77 \cdot 7$ & $\begin{array}{l}170 \cdot 4,30 \cdot 1 \\
(47-394)\end{array}$ & $\begin{array}{l}31 \cdot 3,2 \cdot 3 \\
(18 \cdot 7-50 \cdot 4)\end{array}$ & $\begin{array}{l}1 \cdot 27,0.24 \\
(0.07-2.94)\end{array}$ \\
\hline
\end{tabular}

Notes:

a: number of pigmented cells per unilateral section at the level of the third nerve.

b: density of large, Nissl-containing cells in the area of maximum cell density below the mid-point of the anterior commissure.

c: mean density of cortical Lewy bodies detected using anti-ubiquitin immunocytochemistry in the superior frontal, superior parietal, inferior temporal, entorhinal, insular and anterior cingulate regions.

d: Parkinson's disease.

e: Diffuse Lewy body disease. 


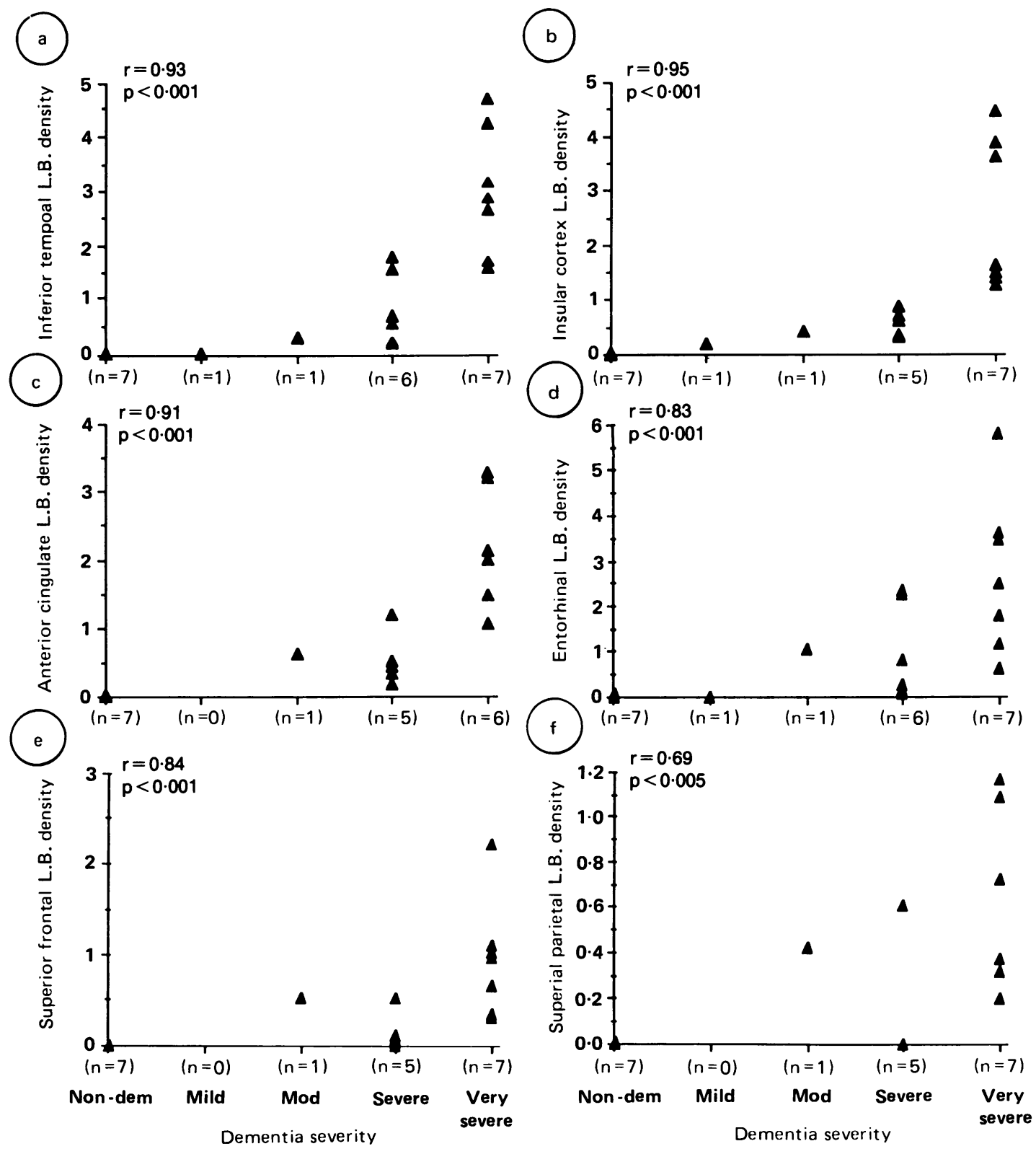

Fig 4 Correlation between dementia severity and cortical Lewy body $(L B)$ density in cases of non-demented Parkinson's disease (non-dem $P D$ ) and diffuse Lewy body disease, in (a) inferior temporal cortex, (b) insular cortex, (c) anterior cingulate cortex, (d) entorhinal cortex, $(e)$ superior frontal cortex and $(f)$ superior parietal cortex. All Lewy body densities expressed as numbers of cortical Lewy bodies per square millimetre. $n=$ number of cases examined in each category (see text $), r$ and $p=$ Spearman's correlation coefficient and probability of the null hypothesis respectively. 


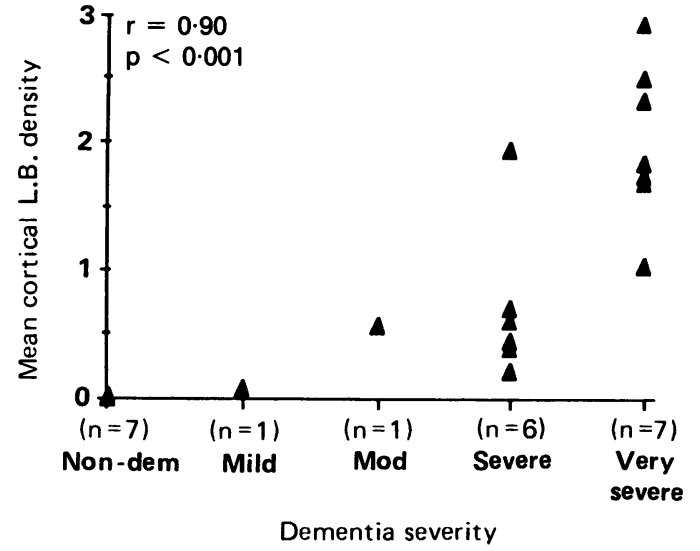

Fig 5 Correlation between dementia severity and mean cortical Lewy body density for all six cortical regions (Lewy bodies per square millimetre).

sensitive anti-ubiquitin immunocytochemistry small numbers were detected in three cases (that is, a total of 1-4 cortical Lewy bodies per case in the six regions quantified; maximum density 0.06 per $\mathrm{mm}^{2}$ ) (table 2 , figures 4 and 5).

In the cases of diffuse Lewy body disease cortical Lewy bodies were found most abundantly in entorhinal, inferior temporal, insular and anterior cingulate cortex, mainly in small and medium sized pyramidal neurons in the deeper cortical layers. Lewy bodies affected up to $4 \%$ of all neurones in the anterior cingulate gyrus. There was a highly significant correlation between dementia severity and cortical Lewy body density in each of these cortical regions $(p<0.001)$ (figure $4 a-d)$. They were less abundant in superior frontal and superior parietal lobes, but here too there was a significant correlation between cortical Lewy body density and dementia severity $(p<0.005)$ (figure $4 \mathrm{e}-\mathrm{f}$ ). A highly significant correlation was also found between the mean cortical Lewy body density in all six cortical regions and dementia severity $(p<0.001)$ (figure 5). Lewy bodies were rare in the hippocampus (and occurred almost exclusively in the subiculum: no Lewy bodies were identified in the dentate gyrus), but again there was a significant correlation between subiculum Lewy body density and dementia severity $(p<0.001)$ (not shown).

\section{Cortical senile plaques}

Senile plaques were found in all fifteen cases of diffuse Lewy body disease (table 3 ). Senile plaque density generally reflected cortical Lewy body density $(p=0.02)$ (figure 6); their density did not correlate with neurofibrillary tangle density as might be expected if the senile plaques were due to coexistent Alzheimer's disease. Indeed, senile plaques were often found in large numbers in cases of diffuse Lewy body disease which showed no other features to support a diagnosis of Alzheimer's disease, such as neurofibrillary tangles, granulovacuolar degeneration or Hirano bodies.

Senile plaques were found in the non-demented Parkinson's disease and control cases in small numbers and therefore compatible with normal ageing. ${ }^{40}$

\section{Cortical neurofibrillary tangles}

Eleven of the fifteen cases of diffuse Lewy body disease had either no hippocampal and neocortical tangles or only small numbers consistent with age (table 3 ). The remaining four cases had neurofibrillary tangles in numbers which satisfy quantitative criteria for the

Table 3 Senile plaque and neurofibrillary tangle density in cases of diffuse Lewy body disease

\begin{tabular}{|c|c|c|c|c|c|c|}
\hline \multirow{2}{*}{$\begin{array}{l}\text { Case } \\
\text { number }\end{array}$} & \multicolumn{2}{|c|}{ Hippocampusa } & \multicolumn{2}{|c|}{ Middle temporal gyrus } & \multicolumn{2}{|c|}{ Superior parietal lobule } \\
\hline & Plaques & Tangles & Plaques & Tangles & Plaques & Tangles \\
\hline $\begin{array}{l}1 \\
2 \\
3 \\
4^{*} \\
5 \\
6 \\
7 \\
8 \\
9 \\
10 \\
11 \\
12 \\
13^{*} \\
14^{*} \\
15^{*}\end{array}$ & $\begin{array}{l}0.6 \\
1.6 \\
0.9 \\
2.4 \\
0 \\
4 \cdot 8 \\
2 \cdot 4 \\
4 \cdot 8 \\
0 \\
1 \cdot 6 \\
2 \cdot 1 \\
0 \\
7 \cdot 6 \\
5.0 \\
4.2\end{array}$ & $\begin{array}{l}0 \\
0.4 \\
0.3 \\
4 \cdot 4 \\
0 \\
4 \cdot 2 \\
0 \cdot 4 \\
0 \cdot 6 \\
1.6 \\
0 \cdot 8 \\
1.8 \\
0 \\
13 \cdot 3 \\
14.5 \\
2.7\end{array}$ & $\begin{array}{l}1 \cdot 09 \\
1 \cdot 14 \\
0.28 \\
3 \cdot 69 \\
0 \cdot 30 \\
1 \cdot 79 \\
1 \cdot 80 \\
1 \cdot 66 \\
1 \cdot 23 \\
1 \cdot 74 \\
2 \cdot 44 \\
0.47 \\
4 \cdot 31 \\
3 \cdot 83 \\
3.47\end{array}$ & $\begin{array}{l}0 \\
0 \\
0.07 \\
0.12 \\
0 \\
0.08 \\
0 \\
0 \\
0.07 \\
0.09 \\
0.07 \\
0.13 \\
2.56 \\
0.04 \\
0.71\end{array}$ & $\begin{array}{l}0 \\
\text { not measured } \\
0 \\
1 \cdot 08 \\
0 \\
1 \cdot 51 \\
0 \\
2 \cdot 71 \\
0.91 \\
0 \cdot 60 \\
4 \cdot 09 \\
\text { not measured } \\
0.84 \\
1.76 \\
2.40\end{array}$ & $\begin{array}{l}0 \\
0 \\
0 \cdot 10 \\
0 \\
0 \\
0 \\
0 \\
0 \cdot 06 \\
0 \\
0 \\
\\
0.59 \\
0.41 \\
0.50\end{array}$ \\
\hline
\end{tabular}

All plaque and tangle densities assessed using thioflavine $\mathrm{S}$ (see text) and expressed as numbers per square millimetre of cerebral cortex. a: mean subiculum

*: cases where a second diagnosis of Alzheimer's disease was considered (see text). 


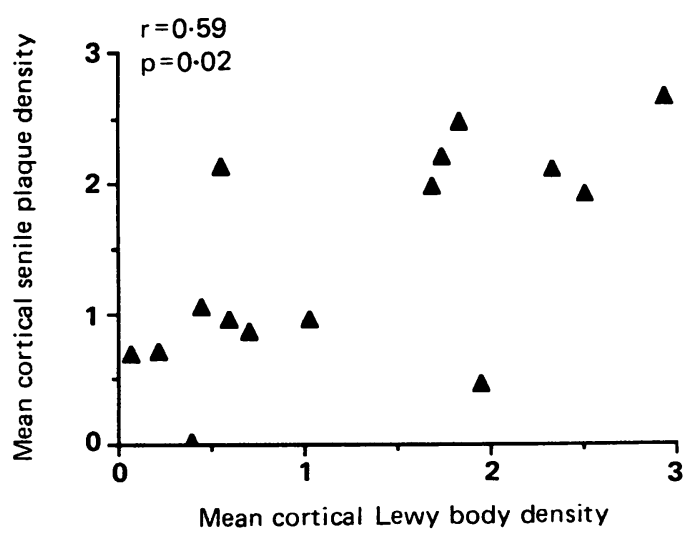

Fig 6 Correlation between mean cortical senile plaque density and mean cortical Lewy body density (both expressed as numbers per square millimetre) in the fifteen cases of diffuse Lewy body disease.

diagnosis of Alzheimer's disease in the hippocampus (Cases 13 and 14) and neocortex (Cases 4 and 15). ${ }^{161741}$ However, one should be cautious in interpreting the significance of tangle counts in isolation: other evidence suggests that a second diagnosis of Alzheimer's disease may be inappropriate in these cases. Firstly, in the cortex Lewy bodies were present in much greater densities than tangles in all four cases. Secondly, dementia severity did not correlate with neurofibrillary tangle density in any region. Thirdly, the morphology and distribution of tangles differed qualitatively from that seen in cases of Alzheimer's disease; individual tangles frequently consisted of very fine perikaryal "wisps" (figure 3) with few classical flame-shaped structures and were confined largely to the mesial temporal lobe.

\section{Other pathology}

No other neuropathological diagnosis was made in the cases of diffuse Lewy body disease. Case 2 had a small lacunar infarction $(8 \mathrm{~mm} \times 2 \mathrm{~mm} \times 4 \mathrm{~mm}$ in maximum extent) in the left medial thalamus, but there was no other significant cerebrovascular lesion and no evidence of Binswanger's disease. Two cases (cases 11 and 13) had moderate spongiform change with vacuolation of the neuropil in the mesial temporal lobe; there was no status spongiosus and no spongiform change in the cerebellum to support a diagnosis of Creutzfeldt-Jakob disease. Five cases (Cases 1, 5, 8, 12 and 13) had small or moderate numbers of swollen achromasic neurons in the temporal cortex. No case, however, showed the pathological features of Pick's disease; there were no strongly argyrophilic inclusion bodies (that is, Pick bodies) in the neocortex and no inclusion body of any kind in the dentate gyrus of the hippocampus. Care was taken to exclude other potentially confusing differential diagnosis; there was no evidence of postencephalitic parkinsonism, progressive supranuclear palsy, Hallervorden-Spatz disease, corticobasal or striatonigral degeneration.

\section{Discussion}

The common syndrome of parkinsonian dementia has in the past been attributed to the cortical and subcortical pathology of Alzheimer's disease, either alone or in combination with brainstem Parkinson's disease pathology. ${ }^{113141542}$ This study of diffuse Lewy body disease shows that a less complex explanation may suffice: parkinsonism may be related to brainstem Lewy bodies and dementia to their cortical counterparts. Before turning to the evidence supporting this explanation, it is worth emphasising it has only become a plausible possibility with the demonstration that diffuse Lewy body disease is common. ${ }^{2}$ In the year surveyed for this study, 15 cases of diffuse Lewy body disease were identified amongst 55 cases of dementia (in a series of 216 unselected referrals), making diffuse Lewy body disease the commonest cause of dementia after Alzheimer's disease. Further studies of subsequent years have confirmed that diffuse Lewy body disease is not rare, and that in cases coming to post mortem it has an incidence comparable to that of vascular dementia (unpublished observations). These observations have been confirmed elsewhere: Forno and Langston identified 13 cases in an unselected series of 260 brains $^{43}$ whilst Perry et al have re-examined a series of 91 brains from elderly demented patients in Newcastle, identifying 14 cases similar to those described here (which they term senile dementia of Lewy body type). ${ }^{44}$

\section{Pathological basis of dementia in diffuse Lewy body disease}

The most striking finding in this series is that dementia severity is closely related to cortical Lewy body density (figures 4 and 5). This suggests that cortical Lewy bodies are a marker for the pathological process responsible for the dementia of diffuse Lewy body disease and that the process is primarily cortical. This accords well with the clinical observation that patients with diffuse Lewy body disease (like severely demented patients with Parkinson's disease ${ }^{45}{ }^{46}$ ) generally show features of cortical dementia such as aphasia, agnosia and apraxia. ${ }^{1}$ The Lewy bodies may not strictly speaking be the direct cause of the dementia, but since the presence of a Lewy body is likely to disrupt the function of a neuron and since they are found in up to $4 \%$ of all cortical neurons (and 
a much higher percentage of the deeper cortical neurons in which they are concentrated) the Lewy bodies themselves may well contribute significantly to the devastating loss of intellectual function suffered by these patients. However, associated pathological features such as cortical neuron loss and senile plaques (discussed below) may also contribute; cortical neuron density has not been measured in this study but the finding of areas of cortical gliosis and spongiosis suggests neuronal loss. In this respect (as with the brainstem Lewy body where massive cell loss in the substantia nigra is associated with relatively small numbers of Lewy bodies in remaining neurons) the cortical Lewy body may be simply a marker of a process which is causing more widespread neuronal damage.

This study does not support the concept of a subcortical basis for the dementia in the nucleus basalis of Meynert. This nucleus has received considerable attention as it is the principal source of extrinsic cholinergic innervation to the cerebral cortex $\mathrm{x}^{478}$ and shows massive cell depletion in cases of Alzheimer's disease. ${ }^{49-51}$ Since cell loss from the nucleus basalis of Meynert also occurs in Parkinson's disease $\mathrm{e}^{5253}$ and is most marked in demented patients, it has been suggested that this might be an important cause of parkinsonian dementia. In the present series, cell density was slightly lower in the demented cases of diffuse Lewy body disease than in the non-demented cases of Parkinson's disease but the difference between the groups was not statistically significant (table 2). Furthermore, in individual cases there was no significant correlation between dementia severity and nucleus basalis of Meynert neuronal density. These findings suggest that cell loss from the nucleus basalis of Meynert does not make a major contribution to the dementia of diffuse Lewy body disease. However, a lesser contribution cannot be excluded on the basis of these limited estimates of cell density. Although the sampling of the nucleus basalis of Meynert was carefully standardised, it remains liable to error and a study of total cell counts in serial sections, together with neurochemical measurement of cholinergic projections to the cerebral cortex, would be necessary to resolve this important issue. Reductions in the cholinergic marker choline acetyltransferase have been reported in two small groups of cases of diffuse Lewy body disease ${ }^{2154}$ but it is not yet clear if this reduction relates to the dementia and in particular if it is greater than the reduction seen in non-demented cases of Parkinson's disease.

Relationship between diffuse Lewy body disease and Alzheimer's disease

Dementia in these cases could not, in general, be attributed to Alzheimer's disease. None of the cases showed neurofibrillary tangles in the dorsal raphe nucleus, the nucleus basalis of Meynert or in other subcortical nuclei in the manner which is characteristic of Alzheimer's disease..$^{55}$ Eleven of the cases did not have significant numbers of neurofibrillary tangles in the hippocampus and neocortex (table 3); in the four cases with larger numbers of cortical tangles, these were invariably exceeded by the numbers of cortical Lewy bodies and did not occur with the morphology and distribution normally seen in Alzheimer's disease. ${ }^{5657}$

Senile plaques were common. This should not, however, be taken as evidence of Alzheimer's disease. Plaques occur in a range of neurodegenerative disorders and are not a specific hallmark of Alzheimer's disease. ${ }^{58}$ In this series, plaque density paralleled the density of cortical Lewy bodies (figure 6), and in many cases large numbers of plaques occurred without any other evidence of Alzheimer's disease (such as neurofibrillary tangles, granulovacuolar degeneration or Hirano bodies). Similar cases, with many cortical Lewy bodies and senile plaques but few or no neurofibrillary tangles, have been reported by others, ${ }^{20-225960}$ suggesting that senile plaques are part of the pathology of diffuse Lewy body disease.

This conclusion has important practical implica-a tions for the study of Alzheimer's disease. Recent neuropathological criteria for the diagnosis of 2 Alzheimer's disease have laid great weight upon $z$ estimates of plaque density especially in older cases. ${ }^{61} 8$ Some authors have even suggested that there may be a을 "plaque-only" subgroup of Alzheimer's disease lack ing the other pathological features of the disease. .2 . Such cases must be examined carefully for cortical Lewy bodies, preferably using the technique of antiubiquitin immunocytochemistry since cortical Lewy bodies are difficult to identify on routine $\mathrm{H}$ and $\mathrm{E}$ stains. It is very likely that some of these cases are in fact examples of diffuse Lewy body disease.

Distinguishing diffuse Lewy body disease (that is, brainstem and cortical Lewy bodies and cortical plaques) from mixed Parkinson's disease and Alzheimer's disease (that is, brainstem Lewy bodies and tangles, and cortical tangles and plaques) is also of major theoretical importance. Failure to do so would provide spurious support for the suggested association between Parkinson's disease and Alzheimer's disease, ${ }^{14} 15$ which in turn promotes speculation that the two diseases may share a common vulnerability or a common cause. Previous reports describing such an association should perhaps be reviewed in the light of current knowledge of the pathology of diffuse Lewy body disease. It is possible that once cases of diffuse Lewy body disease have been identified, remaining genuine cases of mixed Parkinson's disease and Alzheimer's disease will have a statistical rather than a biological explanation. ${ }^{63}$ 
Relationship between diffuse Lewy body disease and Parkinson's disease

The clinical features in diffuse Lewy body disease are frequently very similar to those of Parkinson's disease ${ }^{1}$ (table 1). This study confirms previous reports that there is also considerable pathological overlap. In particular the brainstem pathology of the two diseases is for practical purposes indistinguishable, with both showing cell loss, gliosis and classical Lewy body formation in the substantia nigra, locus ceruleus and other brainstem nuclei. The only difference identified by this study is that a greater proportion of the remaining substantia nigra neurons contain Lewy bodies in diffuse Lewy body disease, raising the possibility that there is an increased tendency to Lewy body formation in this disease.

There is also pathological overlap in the nucleus basalis of Meynert, as discussed above. The striking difference between non-demented Parkinson's disease and diffuse Lewy body disease lies in the numbers of cortical Lewy bodies. No cortical Lewy body was detected in four of the seven cases of non-demented Parkinson's disease despite an extensive search using anti-ubiquitin immunocytochemistry. In the remaining three cases Lewy bodies were not detected using routine $\mathrm{H}$ and $\mathrm{E}$ stains but anti-ubiquitin immunocytochemistry revealed small numbers, for example, between 1 and 3 Lewy bodies in the insular cortex (that is, $0.01-0.04$ Lewy bodies $/ \mathrm{mm}^{2}$ ) and either 0 or 1 Lewy body in entorhinal cortex (that is, 0-0.06 Lewy bodies/ $\mathrm{mm}^{2}$ ) (table 2). Far larger numbers (and greater densities) of Lewy bodies were detected in each of the cases of diffuse Lewy body disease. The small number of cortical Lewy bodies found in non-demented cases of Parkinson's disease is consistent with the hypothesis that dementia is related to cortical Lewy body density with symptoms of cognitive impairment developing only when a certain threshold has been exceeded. This "spectrum hypothesis" was first proposed by Yoshimura et $a^{2064}$ who classified cases of Lewy body disease into three groups, from Group $C$ who had classical Parkinson's disease without dementia and brainstem but not cortical Lewy bodies, through to Group A (which they termed diffuse Lewy body disease) who were demented and had large numbers of cortical Lewy bodies as well as brainstem Lewy bodies. Between these groups lay Group B termed "transitional Lewy body disease", which had brainstem Lewy bodies but fewer cortical Lewy bodies and a lower incidence of dementia. If one accepts this hypothesis (without necessarily accepting its nomenclature), it follows that diffuse Lewy body disease can only be distinguished pathologically from Parkinson's disease by applying essentially arbitrary diagnostic criteria based on quantitative estimates of cortical Lewy body density. It would seem reasonable to select the density at which symptoms of dementia first appear, but this point is difficult to define clinically and is in any case poorly represented in this series. On the basis of the present series it is possible to propose provisional criteria which have the advantage of practical simplicity. For example, in the anterior cingulate gyrus (which is small, easy to scan and invariably affected in cases of diffuse Lewy body disease in our experience) the presence of more than 12 cortical Lewy bodies in an anti-ubiquitin immunocytochemistry preparation or more than five on an $\mathrm{H}$ and $\mathrm{E}$ preparation would include all the moderate to very severely demented cases (that is, those demented by conventional criteria ${ }^{65}$ ), but exclude the nondemented Parkinson's disease cases. It must, however, be emphasised that such definitions are tentative and arbitrary. Until larger studies of non-demented PD patients and mildly affected cases of diffuse Lewy body disease are available, it might be prudent to retain the spectrum hypothesis and quantify cortical Lewy body density thoroughly in individual cases.

From this study, however, we can conclude that diffuse Lewy body disease is a common substrate of parkinsonian dementia and that the dementia is related to a cortical process which involves Lewy body and senile plaque formation. Further understanding is likely to develop rapidly, as awareness of the condition increases: in particular clinicians should consider diffuse Lewy body disease in the differential diagnosis of cases of parkinsonian dementia and neuropathologists should seek cortical Lewy bodies with a sensitive technique such as anti-ubiquitin immunocytochemistry.

This study was supported by the Stanhope Trust, the Parkinson's Disease Society and the Special Trustees of the Nottingham University Hospitals. We thank the many doctors who referred cases to this study, Dr F Doherty for assistance in the production of antiubiquitin antibody, Mr D McQuire and Mr K Morrell for expert technical assistance and Mr W Brackenbury for photomicrography.

\section{References}

1 Byrne EJ, Lennox G, Lowe J, et al. Diffuse Lewy body disease: clinical features in fifteen cases. J Neurol Neurosurg Psychiatry, in press.

2 Lennox G, Lowe J, Byrne J, et al. Cortical Lewy body disease: a pathological substrate for dementia in Parkinson's disease. In: Crossman AR, Sambrook MA, eds. Neural mechanisms of disorders of movement, London: John Libbey, 1989:265-8.

3 Brown RG, Marsden CD. How common is dementia in Parkinson's disease? Lancet 1984;ii:1262-5.

4 Pearce J. The extrapyramidal disorder of Alzheimer's disease. Eur Neurol 1974;12:94-103.

5 Drachman DA, Stahl S. Extrapyramidal dementia and levodopa. Lancet 1975;i:809. 
6 Sulkava R. Alzheimer's disease and senile dementia of the Alzheimer type: a comparative study. Acta Neurol Scand 1982;65:636-50.

7 Molsa PK, Martilla RJ, Rinne UK. Extrapyramidal signs in Alzheimer's disease. Neurology 1984;34:1114-6.

8 Chui HC, Teng EL, Henderson VW, Moy AC. Clinical subtypes of dementia of the Alzheimer type. Neurology 1985;35:1544-50.

9 Mayeux R, Stern Y, Spanton S. Heterogeneity in dementia of Alzheimer type: evidence of subgroups. Neurology 1985;35:453-61.

10 Stern Y, Mayeux R, Sano M, et al. Predictors of disease course in patients with probable Alzheimer's disease. Neurology 1987;37:1649-53.

11 Ditter S, Mirra S. Neuropathological and clinical features of Parkinson's disease in Alzheimer's disease patients. Neurology 1987;37:754-60.

12 Ball MJ. The morphological basis of dementia in Parkinson's disease. Can J Neurol Sci 1984;11:180-4.

13 Chui HC, Mortimer JA, Slager U, et al. Pathologic correlates of dementia in Parkinson's disease. Arch Neurol 1986;43:991-5.

14 Hakim AM, Mathieson G. Dementia in Parkinson's disease: a neuropathologic study. Neurology 1979;29:1209-14.

15 Boller F, Mizutani T, Roessmann U, Gambetti P. Parkinson's disease, dementia and Alzheimer's disease: clinicopathological correlations. Ann Neurol 1980;7:329-35.

16 Tomlinson BE, Blessed G, Roth M. Observations on the brains of demented old people. J Neurol Sci 1970;11:205-42.

17 Wilcock GK, Esiri MM. Plaques, tangles and dementia: a quantitative study. $J$ Neurol Sci 1982;56:343-56.

18 Mann DMA, Yates PO. Pathological basis for neurotransmitter changes in Parkinson's disease. Neuropathol Appl Neurobiol 1983;9:3-19.

19 Okazaki H, Lipkin LE, Aronson SM. Diffuse intracytoplasmic ganglionic inclusions (Lewy body type) associated with progressive dementia and quadriparesis in flexion. $J$ Neuropathol Exp Neurol 1961;20:237-44.

20 Kosaka K, Yoshimura M, Ikeda K, Budka H. Diffuse type of Lewy body disease: progressive dementia with abundant cortical Lewy bodies and senile change of varying degree-a new disease? Clin Neuropathol 1984;3:185-92.

21 Dickson DW, Davies P, Mayeux R, et al. Diffuse Lewy body disease: neuropathological and biochemical studies of six patients. Acta Neuropathol (Berl) 1987;75:8-15.

22 Gibb WRG, Esiri MM, Lees AJ. Clinical and pathological features of diffuse cortical Lewy body disease (Lewy body dementia). Brain 1987;110:1131-53.

23 Burkhardt CR, Filley CM, Kleinschmidt-DeMasters BK, et al. Diffuse Lewy body disease and progressive dementia. Neurology 1988;38:1520-8.

24 Forno LS. The Lewy body in Parkinson's disease. Adv Neurol 1986;45:35-43.

25 Lennox G, Lowe J, Morrell K, et al. Anti-ubiquitin immunocytochemistry is more sensitive than conventional techniques in the detection of diffuse Lewy body disease. $J$ Neurol Neurosurg Psychiatry 1989;52:67-71.

26 Kuzuhara $\mathrm{S}$, Mori $\mathrm{H}$, Izumiyama $\mathrm{N}$, et al. Lewy bodies are ubiquitinated: a light and electron microscopic immunocytochemical study. Acta Neuropathol (Berl) 1988;75:345-53.

27 Bancher C, Lassmann $\mathrm{H}$, Budka $\mathrm{H}$, et al. An antigenic profile of Lewy bodies: Immunocytochemistry indication for protein phosphorylation and ubiquitination.J Neuropathol Exp Neurol 1989;48:81-93.

28 Lowe J, Blanchard A, Morrell K, et al. Ubiquitin is a common factor in intermediate filament inclusion bodies of diverse type in man, including those of Parkinson's disease, Pick's disease and Alzheimer's disease, as well as Rosenthal fibres in cerebellar astrocytomas, cytoplasmic bodies in muscle and Mallory bodies in alcoholic liver disease. J Pathol 1988;155: 9-15.

29 Mori H, Kondo J, Ihara Y. Ubiquitin is a component of paired helical filaments in Alzheimer's disease. Science 1987; 235: $1641-4$.

30 Perry G, Friedman R, Shaw G, Chau V. Ubiquitin is detected in neurofibrillary tangles and senile plaque neurites of $\mathrm{Alz}$ heimer's disease. Proc Natl Acad Sci USA 1987;84:3033-6.

31 Cole GM, Timeras PS. Ubiquitin-protein conjugates in Alzheimer's lesions. Neurosci Lett 1987;79:207-12.

32 Lennox G, Lowe J, Morrell $\mathrm{K}$, et al. Ubiquitin is a component of neurofibrillary tangles in a variety of neurodegenerative diseases. Neurosci Lett 1988;94:211-7.

33 Lennox G, Lowe J, Byrne J, et al. Cortical Lewy bodies and the spectrum of Lewy body disease (abstract). J Neurol Neurosurg Psychiatry 1988;51:1358.

34 Byrne EJ, Lennox G, Lowe J, Reynolds G. Diffuse Lewy body disease: the clinical features. Proc Ninth Internat Symp Parkinson's disease, 1988.

35 Cross RB. Demonstration of neurofibrillary tangles in paraffin sections: a quick and simple method using a modification of Palmgren's method. Med Lab Sci 1982;39:67-9.

36 Lowe J, Lennox G, Jefferson D, et al. A filamentous inclusion body within anterior horn neurones in motor neurone disease defined by immunocytochemical localisation of ubiquitin. Neurosci Lett 1988;94:203-10.

37 Sternberger LA. Immunocytochemistry. 3rd edn. New York: Wiley, 1986.

38 Strub RI, Black FW, Organic Brain Syndromes. Philadelphia: FA Davis, 1981:119-64.

39 Reisberg B, Ferris SH, De Leon MJ, Crook T. The global deterioration scale for assessment of primary degenerative dementia. Am J Psychiatry 1982;139:1136-9.

40 Tomlinson BE, Blessed G, Roth M. Observations on the brains of non-demented old people. J Neurol Sci 1968;7:331-56.

41 Ball MJ, Griffin-Brooks S, MacGregor J, et al. Neuropathological definition of Alzheimer disease: multivariate analyses in the morphometric distinction between Alzheimer dementia and normal aging. Alz Dis Assoc 1988;2:29-37.

42 Leverenz J, Sumi SM. Parkinson's disease in patients with Alzheimer's disease. Arch Neurol 1986;43:662-4.

43 Forno LS, Langston JW, Langston JW. The amygdala-parahippocampal region: a predilection site for Lewy bodies (abstract) J Neuropathol Exp Neurol 1988;47:354.

44 Perry R, Irving D, Blessed G, et al. Clinically and neuropath-? ologically distinct form of dementia in the elderly. Lancet 1989;i:166.

45 Mayeux R, Stern Y, Rosen J, Benson DF. Is "subcortical dementia" a recognizable clinical entity? Ann Neurol 1983;14:278-283.

46 Pillon B, Dubois B, Lhermitte F, Agid Y. Heterogeneity of cognitive impairment in progressive supranuclear palsy, Parkinson's disease and Alzheimer's disease. Neurology 1986;36:1179-85.

47 Johnston MV, McKinney M, Coyle JT. Evidence for a cholinergic projection to neocortex from neurones in basal forebrain. Proc Natl Acad Sci USA 1979;76:5392-6.

48 Fibiger HC. The organisation and some projections of the mammalian forebrain. Brain Res Rev 1982;4: 327-88.

49 Whitehouse PJ, Price DL, Struble RG, et al. Alzheimer's disease and senile dementia: loss of neurons in the basal forebrain. Science 1982;215:1237-9.

50 Tagliavini F, Pilleri G. Basal nucleus of Meynert: a neuropathological study in Alzheimer's disease, simple senile dementia, Pick's disease and Huntington's chorea. J Neurol Sci 1983;62:243-60.

51 Perry RH, Blessed G, Tomlinson BE. Histochemical observations on cholinesterase activities in the brains of elderly normal and demented (Alzheimer-type) patients. Age Ageing 1986;9:9-16.

52 Nakano I, Hirano A. Parkinson's disease: neuron loss in the nucleus basalis without concomitant Alzheimer's disease. Ann Neurol 1984;15:415-8. 
53 Whitehouse PJ. Clinical and neurochemical consequences of neuronal loss in the nucleus basalis of Meynert in Parkinson's disease and Alzheimer's disease. Adv Neurol 1986;45:393-7.

54 Clark AW, White CL, Manz HJ, et al. Primary degenerative dementia without Alzheimer pathology. Can J Neurol Sci 1986;13:462-70.

55 Tomlinson BE. The neuropathology of Alzheimer's disease: some issues in need of resolution (The Second Dorothy Russell Memorial Lecture). Neuropathol Appl Neurobiol in press.

56 Pearson RCA, Esiri MM, Hiorns RW, et al. Anatomical correlates of the distribution of the pathological changes in the neocortex in Alzheimer's disease. Proc Natl Acad Sci USA 1985;82 4531-4.

57 Perry RH. Recent advances in neuropathology. Br Med Bull 1986;42:34-41.

58 Tomlinson BE, Corsellis JAN. Ageing and the dementias. In: Hume Adams J, Corsellis JAN, Duchen LW, eds. Greenfield's Neuropathology, 4th edn. London: Edward Arnold, 1984; 951-1025.

59 Mitsuyama Y, Fukunaga H, Yamashita M. Alzheimer's disease with widespread presence of Lewy bodies. Folia Psychiatrica et Neurologica Japonica 1984;38:81-8.

60 Sima AAF, Clark AW, Sternberger NA, Sternberger LA. Lewy body dementia without Alzheimer changes. Can J Neurol Sci 1986;13:490-7.

61 Khachaturian ZS. Diagnosis of Alzheimer's disease. Arch Neurol 1985; 42:1097-105.

62 Terry RD, Hansen LA, DeTeresa R, et al. Senile dementia of the Alzheimer type without neocortical neurofibrillary tangles. $J$ Neuropathol Exp Neurol 1987;46:262-8.

63 Quinn NP, Rossor MN, Marsden CD. Dementia and Parkinson's disease: pathological and neurochemical considerations. $\mathrm{Br}$ Med Bull 1986;42:86-90.

64 Yoshimura M. Cortical changes in the parkinsonian brain: a contribution to the delineation of "diffuse Lewy body disease". J Neurol 1983;229:17-32.

65 American Psychiatric Association Task Force on Nomenclature and Statistics. Diagnostic and Statistical Manual, 3rd edn. (revised) (DSM III R). Washington: American Psychiatric Association, 1988:103-17. 